\title{
Synthesis of \\ Porous Inorganic Membranes
}

\section{Michael Tsapatsis and George R. Gavalas}

\section{Introduction}

Here we will attempt a brief overview of recent synthetic efforts for micropore and lower-end mesopore membranes. We will not address the very important classes of nonporous membranes, such as dense metals and solid electrolytes with applications in $\mathrm{H}_{2}$ and $\mathrm{O}_{2}$ separations, or meso- and macroporous membranes, which find applications in food processing and water treatment. Microporous materials provide high permselectivities for molecules encountered in the chemical-processing industry but suffer from low intrinsic permeabilities. Therefore, in order to bring microporous membrane materials to commercial applications, functional composites with small effective thicknesses (in the micron or submicron range) must be developed. For example, to achieve economical membrane-reactor sizes, fluxes as high as $0.1 \mathrm{~mol} /\left(\mathrm{m}^{2} \mathrm{~s}\right)$ are desirable. ${ }^{1}$ Approaches to microporous membranes include modification of mesoporous membranes by sol-gel and chemical-vapor-deposition (CVD) techniques, carbonization of polymers to form molecular-sieve carbon, and polycrystalline-film growth of zeolites and other molecular sieves.

\section{Carbon Membranes}

Microporous carbon is widely used for liquid or gas purification because of its strong adsorptive properties and high surface area. It is also used for air separation by pressure swing adsorption (PSA), relying on its adsorptive and molecularsieving properties. From the standpoint of applications, microporous carbons are classified into activated carbons with pore size $0.8-2 \mathrm{~nm}$, and ultramicroporous carbons or carbon molecular sieves with pores $0.3-0.6 \mathrm{~nm}$. Activated carbons are used because of their strong adsorption properties, while carbon molecular sieves are useful on account of their molecular-sieving as well as adsorption properties.

Microporous carbons are of ten classified into graphitizing and nongraphitizing. ${ }^{2-4}$ Graphitizing carbons are produced from precursors that melt during heat treatment, forming a mesophase structure. This partially ordered structure is maintained upon solidification and turns into graphite at temperatures above $1400^{\circ} \mathrm{C} .{ }^{2}$ Graphitizing carbons are produced from materials such as petroleum pitch, and from polymers such as poly(vinyl chloride) (PVC) and polyimides (PIs).

Nongraphitizing carbons, also known as glassy carbons, result from heating polymeric precursors, which are initially crosslinked or become crosslinked before the onset of decomposition. The crosslinked solid lacks the mobility to attain long-range order and, upon heat treatment, turns into a network of randomly oriented platelets or ribbons. Heating above $2000^{\circ} \mathrm{C}$ can cause development of long-range order by coalescence of the ribbonlike elements. Precursors of such carbons include low-rank coals, cellulose, and synthetic polymers such as poly (furfuryl alcohol) (PFA), phenolic resins, and poly(vinylidene chloride) (PVDC). Carbons formed by decomposition on $\mathrm{Fe}, \mathrm{Ni}$, or $\mathrm{Co}$ of gas mixtures containing $\mathrm{CO}$, $\mathrm{CH}_{4}$, and other small hydrocarbons have intermediate structure between graphitizing and nongraphitizing. ${ }^{5}$

The carbon literature contains numerous reports dealing with the characterization of porous carbons by adsorption of probe molecules and the effect of the heating protocol on total pore volume and pore size. There is little information, however, about the relationship between precursor structure and pore structure of carbon.

Porous structure aside, the mechanical properties of carbon membranes are of critical importance in applications. Considerable information is available about the effect of processing conditions on the mechanical properties of carbon fibers from coal-tar pitch, polyacrylonitrile (PAN), and PI precursors. Carbonization studies of these polymers have shown that flow-induced orientation generated during fiber spinning and drawing persists in subsequent carbonization and is conducive to high tensile and flexural strength. ${ }^{6-9}$ Align ment of poly mer chains or liquid crystals is expected to favor dense bonding normal to the fiber axis, imparting high tensile strength to the carbon fibers. In nongraphitizing carbons, the spatial pattern of bonding is more random and less dense on account of the more random orientation of the microscopic platelets referred to earlier. Nongraphitizing carbons obviously have lower tensile and flexural strength.

\section{Hollow-Fiber (Unsupported) \\ Membranes}

To obtain hollow-fiber membranes of high permeance, it is necessary to start from an asymmetric (skinned) polymeric hollow fiber having a thin, nonporous skin $(0.05-1 \mu \mathrm{m})$, providing the separation properties, and a porous substructure serving as a support, with an intermediate layer of increasing pore size. This layered structure is generated either by exploiting the spatial gradients developing during polymer gelation (phase inversion) or in a separate coating step. If the asymmetric structure could be preserved during the carbonization process, it would be possible to make membranes of very high permeance. Using, for example, a permeability of $10^{3}$ Barrer for $\mathrm{H}_{2}$ or $\mathrm{O}_{2}{ }^{10}$ yields a permeance of $3.4 \times 10^{-6} \mathrm{~mol} /\left(\mathrm{m}^{2} \mathrm{~s} \mathrm{~Pa}\right)$ for a $0.1-\mu \mathrm{m}$ skin, assuming negligible resistance outside the skin. If, on the other hand, the porosity collapsed during carbonization, rendering the whole fiber microporous, it would reduce the permeance by a factor of 500 , assuming a $50-\mu \mathrm{m}$ wall thickness. It transpires that one of the critical issues in carbon-membrane preparation is the preservation of the pores of the substructure and transition layer during carbonization.

Hollow-fiber carbon membranes were first reported by Koresh and Soffer, ${ }^{10}$ who articulated the main advantages of carbon membranes relative to polymeric membranes. These first membranes were made from cellulosic-fiber precursors. In later work, PI precursors were employed because of two exceptionally favorable properties: high glass-transition temperature, preventing melting or softening 
during carbonization; and a high degree of orientation attained by the flat and rigid polymer chains during fiber spinning and drawing. The chains are strongly held in alignment by secondary bonds, ${ }^{7-9}$ and this alignment is preserved during carbonization, despite the about $40 \%$ mass loss. Asymmetric PI hollow-fiber membranes are made commercially by two companies for application to hydrogen separation from refinery streams.

Jones and Koros ${ }^{11}$ studied the preparation and permeation properties of carbon membranes using Medal PI fiber precursors. A key trend, found in other membranes as well, is the higher separation ratio and lower permeance obtained by increasing the carbonization temperature. Noteworthy is the value of the $\mathrm{O}_{2}: \mathrm{N}_{2}$ separation ratio obtained for air, between 11 and 13, which is about twice the ratio afforded by commercial polymeric membranes of comparable oxygen permeance $\left[5 \times 10^{-9} \mathrm{~mol} /\left(\mathrm{m}^{2} \mathrm{~s} \mathrm{~Pa}\right)\right]$. Likewise, the separation ratio for the $\mathrm{CO}_{2}-\mathrm{CH}_{4}$ mixture was about two or three times that of polymeric membranes possessing similar $\mathrm{CO}_{2}$ permeance $\left[1.8 \times 10^{-8} \mathrm{~mol} /\left(\mathrm{m}^{2} \mathrm{~s} \mathrm{~Pa}\right)\right]$.

An important advance in the technology of hollow-fiber carbon membranes was recently reported by Kusuki et al. of Ube Industries. ${ }^{12}$ Using hollow fibers made of a different PI, these researchers developed a continuous carbonization process in which the fiber is passed through the furnace in $3.6 \mathrm{~min}$ and collected around a bobbin. The short heating time was possible by using high furnace temperatures, $700-850^{\circ} \mathrm{C}$. With the exception of ethylene, the order of permeances is in inverse relation to the order of their Lennard-Jones molecular diameters, indicating separation primarily by molecular sieving. $\mathrm{H}_{2}$ permeance of $7.5 \times 10^{-8} \mathrm{~mol} /\left(\mathrm{m}^{2} \mathrm{~s} \mathrm{~Pa}\right)$ was obtained with $\mathrm{H}_{2} / \mathrm{CH}_{4}$ permselectivity of $\sim 200$. Contrary to conventional wisdom, the work of the Ube group shows that a very slow heating rate is not necessary for making selective carbon membranes. Short heat-treatment time of only a few minutes, versus several hours employed in other work, translates into lower membrane production cost.

\section{Supported Carbon Membranes}

In the case of hollow-fiber membranes, strength and handling requirements dictate that the fiber wall must have a thickness of at least some tens of microns. These membranes must consequently have asymmetric structure; otherwise, the thick uniform layer of microporous carbon would have very low permeance.
Supported membranes are not subject to this limitation, for they can be made as thin as $1 \mu \mathrm{m}$ using sufficiently smooth supports (Figure 1). A series of studies by Morooka, Kusakabe, and collaborators at Kyushu University ${ }^{13,14}$ employed a PI precursor. Despite the different precursors and carbonization protocols, the $\mathrm{CO}_{2}$ and $\mathrm{CH}_{4}$ permeance of the supported membrane from Kyushu University was very similar to that of the hollow-fiber membrane from Ube.

In addition to PIs, PFA and phenolic resins have also been used as precursors of supported carbon membranes. Kita et al. ${ }^{15}$ carbonized phenolic resin coated on macroporous $\alpha-\mathrm{Al}_{2} \mathrm{O}_{3}$ or on mesoporous silica. An intermediate siliconerubber coating was used in some cases to smooth out the ceramic support surface and prevent penetration of the phenolic polymer in the pores. Despite the repeated coating and carbonization cycles, these membranes had higher permeance and lower selectivities than the PI-derived membranes, signifying the critical role of the precursor polymer.

Researchers at Air Products and Chemicals (AP) prepared a different type of carbon membrane by coating porous graphite disks $(0.7-\mu \mathrm{m}$ mean pore diameter) with a PVDC latex, heating them to $1000^{\circ} \mathrm{C}$ at $1^{\circ} \mathrm{C} / \mathrm{min}$, and maintaining that temperature for $3 \mathrm{~h} \cdot{ }^{16}$ Among the several distinct trends of the data, we note the very high permeance of hydrocarbon gases, compared with those for the other membranes. Under these conditions, the separation factor of butane to hydrogen was over 100 . These results underline the dominant effect of adsorption over molecular sieving for the AP membranes. In addition to using a different polymer, the AP membranes were prepared using carbonization at $1000^{\circ} \mathrm{C}$, essentially eliminating all heteroatoms and thus modify-

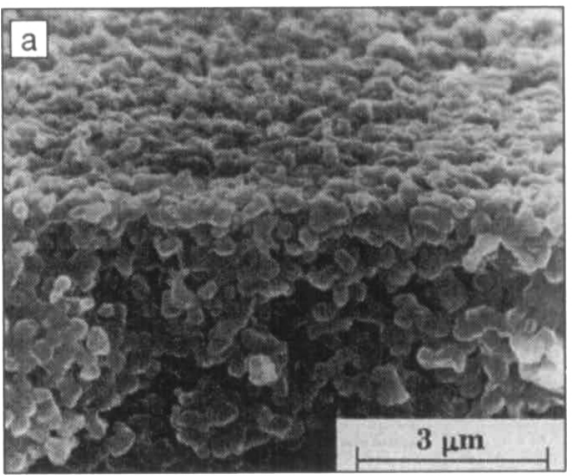

Figure 1. (a) $\mathrm{Al}_{2} \mathrm{O}_{3}$ substrate and (b) supported carbon membrane. ${ }^{13}$

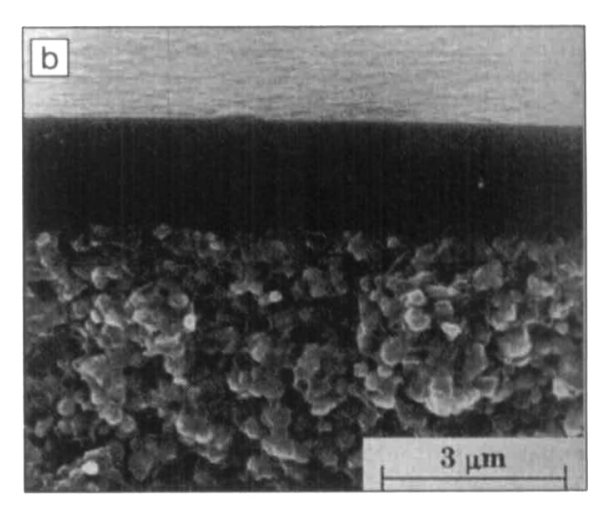

ing the surface properties. The question, of course, remains as to which of the structural features of the PVDC polymer allows heating for 3 hours at a temperature as high as $1000^{\circ} \mathrm{C}$ without excessively narrowing the pores. ${ }^{17}$

The preparation protocols discussed in this section for supported membranes included repeated coating and carbonization cycles, each of these coatings adding $0.5-1 \mu \mathrm{m}$ of carbon. A total thickness of pinholes, given the about $1-\mu \mathrm{m}$ roughness of the macroporous supports. Further research into alternative polymers and coating procedures is required to eliminate the need for multiple processing cycles and reduce the membrane thickness.

\section{Sol-Gel Membranes}

Sol-gel preparation of mesoporous and microporous membranes involves coating a porous support with a suitable colloidal solution (sol), followed by drying and thermal treatment. During drying, the sol undergoes gelation and further crosslinking, which is completed during thermal treatment. ${ }^{18-21}$ The colloidal particles in the coating sol may be dense or polymeric in nature. A sol of dense boehmite particles is widely used to form mesoporous $\gamma-\mathrm{Al}_{2} \mathrm{O}_{3}$ layers on top of macroporous $\alpha-\mathrm{Al}_{2} \mathrm{O}_{3}$ supports. ${ }^{21-24}$ These layers show selectivities, according to the Knudsen diffusion mechanism, too low for gas separations but commercially usable as ultrafiltration membranes. They also serve as supports for further coating with sols of branched silicate polymers formed by acid-catalyzed hydrolysiscondensation of silicon alkoxides. The resulting ultramicroporous layers have high selectivity for a variety of gas separations. ${ }^{25-28}$ The degree of branching of the precursor sols, along with the com2-5 $\mu \mathrm{m}$ seems to be required to eliminate 
petition between polymerization kinetics and drying rates, determines the deposit pore size, porosity, and defect density. ${ }^{23,29,30}$ De Vos and Verweij, ${ }^{31}$ by using processing in a class- 1000 clean room, prepared amorphous silica coatings of $\sim 30-\mathrm{nm}$ thickness on top of $\gamma$-alumina supports (Figure 2b). Excellent flux, selectivities, and reproducibility have been achieved. For example, the $\mathrm{H}_{2}$ permeance was $2 \times 10^{-6} \mathrm{~mol} /\left(\mathrm{m}^{2} \mathrm{~s} \mathrm{~Pa}\right)$, and the $\mathrm{H}_{2} / \mathrm{CH}_{4}$ permselectivity was more than 500 at $200^{\circ} \mathrm{C}$. The reduction in concentration of airborne particles, which introduce defects in the membrane, was found to be necessary for the reproducible production of these membranes. Despite the excellent performance of these membranes, scale-up for module production and stability, especially in the presence of water, ${ }^{32}$ need to be addressed

Introduction of surfactants during silica and other oxide formation can lead to periodic inorganic-organic mesostructures which upon removal of the surfactant template form well-ordered arrangements of pores (hexagonal, cubic, etc.). ${ }^{33,34}$ Although considerable effort has been devoted to demonstrating the ability to form oriented, surfactant-templated materials by using magnetic ${ }^{35}$ and flow-induced ${ }^{36}$ orientation, as well as substrate $-{ }^{37}$ or confinementinduced ${ }^{38}$ ordering, until recently no microstructure appropriate for membrane applications has been achieved using these approaches. This is mainly due to the tendency of these materials to grow with their channels oriented parallel to the solution-substrate interface and to form grains rather than smooth continuous films. A recent promising approach that involves continuous formation of supported cubic and hexagonal mesoporous films by sol-gel dip coating was demonstrated by workers at Sandia National Laboratories, the University of New Mexico, and the University of CaliforniaLos Angeles. ${ }^{39}$ Using this process, they were able to form cubic mesophases in which the pores can be directly accessed from the film surface (Figure 2a). However, a similarly accessible arrangement of the hexagonal mesophase, with pores perpendicular to the substrate, has not been achieved. The method offers fast processing of very smooth and continuous films. Due to their smoothness and continuity, these mesoporous silica films can be used as intermediate layers between the substrate and the final $\mathrm{mi}$ croporous layer prepared by the sol-gel process (e.g., in place of the $\gamma$-alumina layer of de Vos and Verweij ${ }^{31}$ ). In addition to the surfactant-templated mesoporous oxides, where the structure direction is
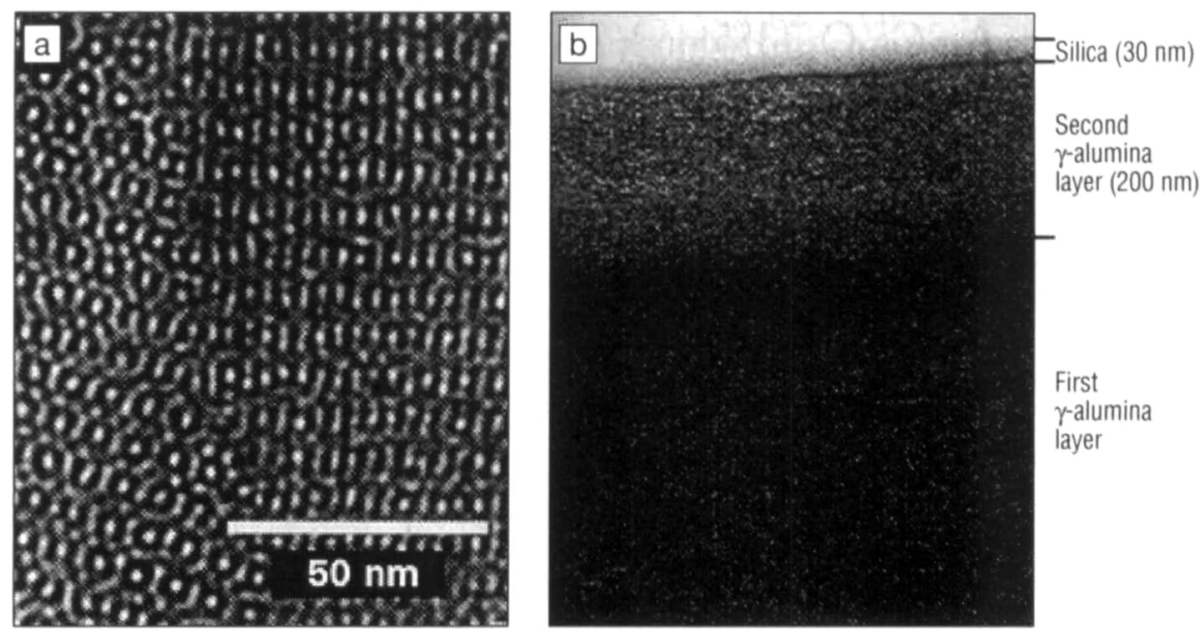

\begin{abstract}
Figure 2. (a) Top view transmission electron microscopy (TEM) of mesoporous membrane with directly accessible channels prepared by coating from a surfactant silicate solution. ${ }^{39}$ (b) TEM cross section of multilayer membrane prepared by dip coating. ${ }^{31}$ On top of the $200 \mathrm{~nm} \gamma-\mathrm{Al}_{2} \mathrm{O}_{3}$ layer, a $30-\mathrm{nm} \mathrm{SiO} \mathrm{O}_{2}$ microporous layer has been deposited.
\end{abstract}

achieved through noncovalent bonding, other synthetic strategies involve use of organic ligands covalently bonded to the siloxane network. ${ }^{40}$ Membranes prepared using this strategy on substrates modified with the mesoporous smooth and continuous overlayers ${ }^{39}$ show selectivities and fluxes for permanent gases similar to those reported by de Vos and Verweij, ${ }^{31}$ but in addition provide the potential for zeolitelike selectivities by offering the choice of the imprinting organic ligand..$^{41,42}$

\section{Zeolite Membranes}

Zeolites and other microporous molecular sieves have unique properties due to their crystalline structure, which consists of a network of well-defined pores and/or cages. Each of the about 100 available structure types has its own distinct pore size, shape, and interconnectivity (the structure types and codes are listed and described in Reference 43). Zeolite pore openings range from $0.3 \mathrm{~nm}$ (smallpore zeolites) to $1 \mathrm{~nm}$ (extra-large-pore zeolites), and their framework constitution can provide for hydrophobic, hydrophilic, acidic, or basic properties. This combination of properties gives the ability to adsorb, interact, and discriminate molecules based on size, shape, and chemical constitution, of ten with precisions at the $1-\AA$ scale. Zeolites in powder form are currently used extensively.as size/shape-selective heterogeneous catalysts and in gas separation and purification processes, as well as ion exchange, desiccation, and sorption. The fabrication of zeolite films has attracted interest in the last decade due to the potential use of these films as selective membranes, electrodes, sensors, and optoelectronic devices. ${ }^{44,45}$

Zeolites are synthesized hydrothermally from precursor silicate or aluminosilicate gels or colloidal suspensions in the presence of organic and inorganic bases or acids, which catalyze hydrolysis and condensation reactions and at the same time act as structure-directing agents (SDAs), stabilizing the open framework structures. ${ }^{46,47}$ The lack of quantitative information on the interplay of chemistry and transport in zeolite synthesis makes it difficult to devise appropriate schemes for film formation. Moreover, the mechanical properties of these materials are not well understood. It is known that zeolite unit cell dimensions and symmetry can change under heating, during SDA removal, or upon adsorption, especially of molecules with dimensions close to the channel dimensions. ${ }^{48}$ To what extent these structural changes may affect the long-term performance of zeolite membranes remains to be addressed.

Early studies report on membranes prepared by embedding zeolite MFI in silicone rubber ${ }^{49}$ and their use in pervaporation to separate alcohols from aqueous solutions. In a similar approach, zeolite composite films were prepared in a glassy silica matrix. ${ }^{50}$ The nature of the interface of the zeolite deposit obviously plays a dominant role in these strategies and remains an issue still to be addressed in sufficient detail. 
Zeolite membranes prepared using an in situ crystallization method have been reported for zeolite LTA, ${ }^{5 t-53} \mathrm{MFI}{ }^{54-67}$ and other types. ${ }^{68-70} \mathrm{~A}$ variety of substrates was used to support the zeolite membranes, including porous alumina and stainless steel, and permeation results for such membranes demonstrate their potential for gas separations. Although in situ growth has been shown to work for several molecular sieves, it gives little flexibility for control over the microstructure of the final films, since synthetic conditions have to be optimized for nucleation and growth in a single- or repeated-batch preparation.

Zeolite-film synthesis using microwave heating has been reported for several zeolite types. ${ }^{71-74}$ Reports demonstrate that microwave synthesis allows for shorter crystallization times due to the increased heating rate. For synthesis of $\mathrm{AlPO}_{4}-5$ (structure type AFI) films on anodized alumina, microwave heating showed suppression of nucleation outside of the substrate pores. It has also been claimed ${ }^{75}$ that convective flow in the substrate pores due to microwave heating aligns particles within the substrates. Although highly selective membranes prepared by microwave treatment have not been demonstrated, the high growth rates hold promise for the fast processing of zeolite films, if production rates will become an issue for commercial application.

Zeolite membranes have also been prepared using the vapor-phase-transport method (VPT). ${ }^{76,77}$ The membrane support is first coated with a compact, dry, amorphous gel using conventional dip coating. Then the coated support is treated in the vapors of triethylamine, ethylenediamine, and water. Films of ANA -, MOR-, FER-, and MFI-type zeolite materials were prepared, and applications to both pervaporation and gas permeation were reported, indicating high selectivities but relatively low fluxes. The proposed growth mechanism states that crystallization starts in a gel layer on the surface of the support and continues into the support pores until a compact layer of zeolite is formed. The selective layer seems to be the one in the interior of the support, although scattered crystals are also formed on the top surface of the support. Usually a one-week treatment is needed for a selective compact layer to be established. The amount of water used during the hydrothermal treatment and the composition and uniformity of the precursor coating are critical parameters that have to be optimized for successful preparations.

In conjunction with the in situ prepa- rations, postsynthetic treatments using a nonzeolitic material to block any nonzeolitic pores in the membrane, increasing the membrane's selectivity, ${ }^{78,79}$ have been proposed. A postsynthetic coking treatment of a ZSM-5 (structure type MFI) membrane was shown to block only the nonzeolitic pores of the membrane, while increasing the $\mathrm{n}$-butane/ $\mathrm{i}$-butane selectivity from 45 to 320 at $180^{\circ} \mathrm{C}^{78} \mathrm{Chemical}$ vapor deposition has also been reported as a pore blocking method. ${ }^{79}$ Despite their beneficial effect on permselectivity, postsynthetic deposition treatments lead to reduced permeance.

Tsapatsis and co-workers proposed the secondary growth technique for the preparation of molecular-sieve films (Figure 3$){ }^{80}$ This processing scheme uses a colloidal zeolite suspension to form a seed layer on a substrate. The seed layer is then hydrothermally grown to eliminate intercrystalline porosity. $\mathrm{MFI}^{81-83} \mathrm{LTA}^{84}$ LTL, ${ }^{85}$ and UTD- ${ }^{86}$ films have been grown using variations of this approach, which, by decoupling nucleation and growth, allows for greater flexibility in choosing hydrothermal synthesis conditions to achieve the desired microstructure. Permselectivity for MFI membranes prepared by secondary growth has been demonstrated. ${ }^{81-83,87}$ This approach allows for preparation of preferentially oriented films based on anisotropic growth rates of the seed particles (Figure 4) or by deposition of oriented seeds. Zeolite-crystal growth rates along different crystallographic directions cannot be predicted; however, observations from grow th in solution can be used in order to achieve de-
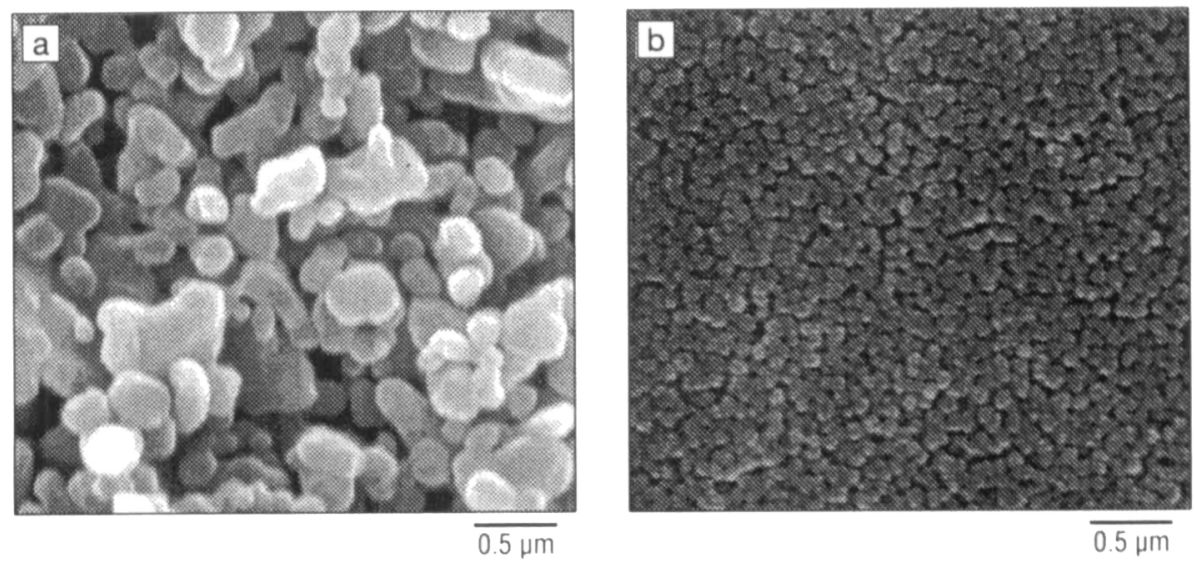

$\overline{0.5 \mu \mathrm{m}}$

MFI Membrane
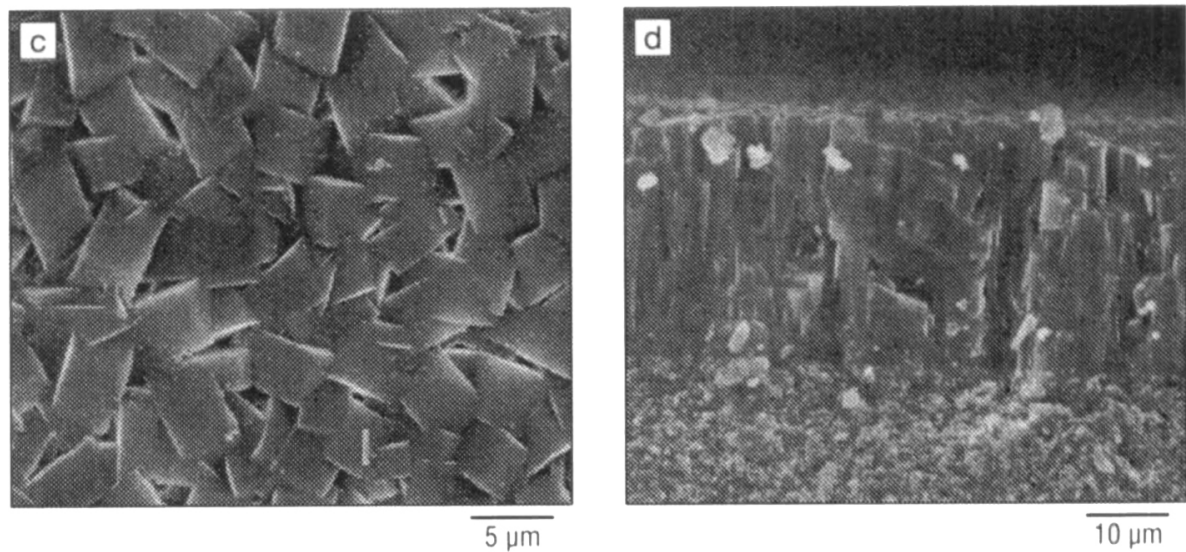

Figure 3. Molecular-sieve films grown by the secondary growth technique, which uses a colloidal zeolite suspension to form a seed layer on a substrate. (a) $\alpha-\mathrm{Al}_{2} \mathrm{O}_{3}$ substrate (support), (b) top view of MFI silicalite seed layer coated on the $\alpha-\mathrm{Al}_{2} \mathrm{O}_{3}$ substrate, (c) top view and (d) cross section of membrane prepared after secondary growth (hydrothermal growth of the seeds). 


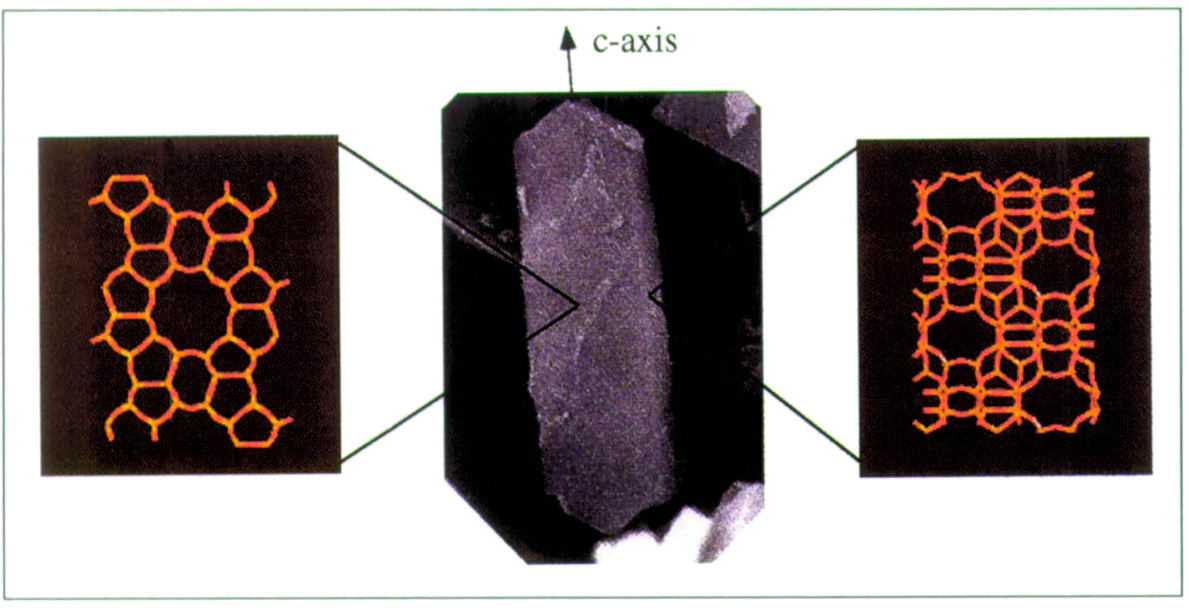

Figure 4. A MFI coffin-shaped crystal grown in solution, illustrating the interconnected straight and "sinusoidal" channel networks of approximately $0.55 \mathrm{~nm}$. In the c-direction, transport pathways exist and involve passing through the channel intersections. Due to faster growth along the $\mathrm{c}$-direction, the membrane shown in Figure 3 has a preferred c-out-of-plane orientation.

sired grain orientation in the membrane. ${ }^{88}$ Although it is still early to judge the commercial potential of zeolite membranes, the considerable progress that has been achieved since the first patent
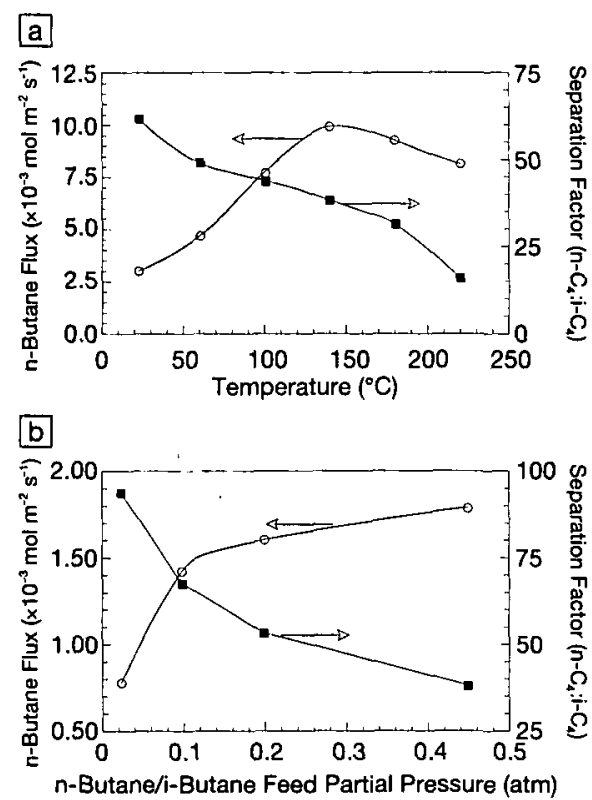

Figure 5. Permeation of butane isomers through MFI membranes prepared using secondary growth Similar behavior is observed for membranes grown by direct (unseeded) crystallization. (a) Effect of temperature. (b) Effect of feed partial pressure. by Suzuki ${ }^{89}$ in 1987 and the recent commercialization of zeolite A membranes for pervaporation ${ }^{90}$ allows for optimism regarding the future of zeolite membranes for more demanding separations. A typical mixture used to judge the quality of MFI-type films is n-butane/i-butane. Mixture selectivities above 50 and fluxes of $\mathrm{n}$-butane $\sim 10^{-3} \mathrm{~mol} /\left(\mathrm{m}^{2} \mathrm{~s}\right)$ have been achieved by both seeded and direct hydrothermal growth (Figure 5). However, similar consistency in other more important mixtures has not yet been demonstrated, ${ }^{91-93}$ illustrating that in addition to the zeolite structure type, the exact membrane microstructure (grain orientation, grain-boundary structure, etc.) can play a dominant role in determining permselectivity.

\section{References}

1. M. Boudart, CATECH 2 (1997) p. 94.

2. F.G. Emmerich, Carbon 33 (1995) p. 47.

3. J.J. Kipling, J.N. Sherwood, V. Shooter, and N.R. Thompson, ibid. 1 (1964) p. 1099.

4. K. Kawamura and G.M. Jenkins, J. Mater. Sci. 7 (1972) p. 315.

5. G.A. Jablonski, F.W. Geurts, A. Sacco, Jr., and R.R. Biederman, Carbon 30 (1992) p. 87.

6. M.Inagaki,K. Sakamoto, and Y.Hishiyama, J. Mater. Res. 6 (1991) p. 1108.

7. W. Pinghua, L. Jie, Y. Zhongren, and L. Rengyuan, Carbon 30 (1992) p. 113.

8. M. Inagaki, S. Harada, T. Sato, T. Nakajima, Y. Horino, and K. Morita, ibid. 27 (1989) p. 253. 9. H. Hatori, Y. Yamada, and M. Shiraishi, ibid. 30 (1992) p. 763.

10. J.E. Koresh and A. Soffer, Sep. Sci. Technol. 22 (1987) p. 973.

11. C.W. Jones and W.J. Koros, Carbon 32 (1994) p. 1419.
12. Y. Kusuki, H. Shimazaki, N. Tanihara, S. Nakanishi, and T. Yoshinaga, J. Membr. Sci. 134 (1997) p. 245.

13. J. Hayashi, M. Yamamoto, K. Kusakabe, and S. Morooka, Ind. Eng. Chem. Res. 34 (1995) p. 4364 .

14. J. Hayashi, H. Mizuta, M. Yamamoto, K: Kusakabe, and S. Morooka, J. Membr. Sci. 124 (1997) p. 243.

15. H. Kita, H. Maeda, K. Tanaka, and K. Okamoto, Chem. Let. 36 (6) (1997) p. 179

16. M.B. Rao and S. Sirkar, J. Membr. Sci. 85 (1993) p. 253.

17. M. Acharya and H.C. Foley, presented at AIChE Meeting, Miami, 1998.

18. C.J. Brinker and G.W. Sherer, Sol-Gel Science (Academic Press, San Diego, 1990).

19. C.J. Brinker, A.J. Hurd, R. Schunk, G.C. Frye, and C.S. Ashley, J. Non-Cryst. Solids 147/ 148 (1992) p. 424.

20. C. Guizard, "Sol-Gel Chemistry and its Application to Porous Membrane Processing," in Fundamentals of Inorganic Membrane Science and Technology, edited by A.J. Burggraat and L. Cot (Elsevier, Amsterdam, 1996).

21. A.J. Burggraaf, "Fundamentals of Membrane Top-Layer Synthesis and Processing," ibid.

22. Y-S. Lin and A.J. Burggraaf, J. Am. Ceram. Soc. 74 (1991) p. 219.

23. R.J.R. Uhlhorn, M.H.B.J. Huis in't Veld, K. Keizer, and A.J. Burggraaf, J. Mater. Sci. 27 (1992) p. 527.

24. C. Klein and N. Giszpenc, Ceram. Bull. 69 (1990) p. 1821.

25. R.S.A. de Lange, J.H.A. Hekkink, K. Keizer and A.J. Burggraaf, J. Membr. Sci. 99 (1995) p. 57. 26. Ibid., Key Eng. Mater. 61/62 (1991) p. 72.

27. S. Kitao and M. Asaeda, J. Chem. Eng. Jpn. 23 (1990) p. 367.

28. N.K. Raman and C.J. Brinker, J. Membr. Sci. 105 (1995) p. 273.

29. A. Cairncross, L.F. Francis, and L.E. Scriven, AlChE J. 42 (1996) p. 55.

30. V. Ng and A. McCormick, J. Phys. Chem. 100 (3) (1996) p. 12517.

31. M. de Vos and H. Verweij, Science 279 (1998) p. 1710.

32. M. Tsapatsis and G.R. Gavalas, J. Membr. Sci. 87 (1994) p. 281.

33. C. Kresge, M. Leonowicz, W. Roth, C. Vartuli, and J. Beck, Nature 359 (1992) p. 710.

34. A. Firouzi, D. Kumar, L.M. Bull, T. Besier, P. Sieger, Q. Huo, S.A. Walker, J.A. Zasadzinski, G. Glinka, J. Nicol, D. Margolese, G.D. Stucky, and B.F. Chmelka, Science 267 (1995) p. 1138 .

35. S. Tolbert, A. Firouzi, G.D. Stucky, and B.F. Chmelka, ibid. 278 (1997) p. 264.

36. H.W. Hillhouse, T. Okubo, J.W. van Egmond, and M. Tsapatsis, Chem. Mater. 9 (1997) p. 1505 .

37. H. Yang, A. Kuperman, N. Coombs, S. Mamiche-Afara, and G.A. Ozin, Nature 379 (1996) p. 703.

38. M. Trau, N. Yao, Y. Xia, G.M. Whitesides, and I.A. Aksay, ibid. 390 (1997) p. 674.

39. Y.F. Lu, R. Ganguli, C.A. Drewien, M.T. Anderson, C.J. Brinker, W.L. Gong, Y.X. Gup, H. Soyez, B. Dunn, M.H. Huang, and J.I. Zink, ibid. 389 (1997) p. 364.

40. N.K. Raman, M.T. Anderson, and C.J. 
Brinker, Chem Mater. 8 (1996) p. 1682. 41. C.J. Brinker (private communication). 42. M.E. Davis, CATECH 1 (1997) p. 19.

43. W.M. Meier and D.H. Olson, Atlas of Zeolite Structure Types (Butterworth-Heinemann, London, 1992).

44. G.A. Ozin, A. Kuperman, and A. Stein, Angezv. Chem. Int. Ed. Engl. 28 (1989) p. 359. 45. M.E. Davis, Ind. Eng. Chem. Res. 30 (1991) p. 1675.

46. R.M. Barrer, Hydrothermal Chemistry of Zeolites (Academic Press, London, 1982).

47. M.E. Davis and R.F. Lobo, Chem. Mater. 4 (1992) p. 56.

48. C-K. Lee and A.S.T. Chiang, J. Chem Soc.Faraday Trans. 92 (1996) p. 3445.

49. H.J.C. Hen nepe, W.B.F. Boswerger, D. Bargeman, M.H.V. Mulder, and C.A. Smolders, J. Membr. Sci, 89 (1994) p. 185.

50. T. Bein, K. Brown, and C.J. Brinker, "Molecular Sieve Films from Zeolite-Silica Microcomposites," in Zeolites: Facts, Figures, Future, edited by P.A. Jacobs and R.A. van Santen (Elsevier Science Publishers, Amsterdam, 1989). 51. G. Myatt, P.M. Budd, C. Price, and S.W. Carr, J. Mater. Chem. 2 (10) (1992) p. 1103. 52. H. Kita, K. Horii, Y. Ohtoshi, K. Tanaka, and K. Ichi, J. Mater. Sci. Lett. 14 (1995) p. 206. 53. M. Kondo, M. Komori, H. Kita, and K. Okamoto, J. Membr. Sci. 133 (1997) p. 133.

54. A. Giroir-Fendler, J. Pereux, H. Mozzanega, and J.A. Dalmon, Stud. Surf. Sci. Catal. 111 (1996) p. 127.

55. C. Bai, M.D. Jia, J.L. Falconer, and R.D. Noble, J. Membr. Sci. 105 (1995) p. 79.

56. E.R. Geus, H. van Bekkum, W.J.W. Bakker, and J.A. Moulijn, Microporous Mater. 1 (1993) p. 131.

57. W.J.W. Bakker, F. Kapteijn, J. Poppe, and J.A. Moulijn, J. Membr. Sci. 117 (1996) p. 57.

58. R.D. Noble and J.L. Falconer, Catal. Today 25 (1995) p. 209.

59. T. Sano, Y. Kiyozumi, M. Kawamura, F. Mizukami, H. Takaya, T. Mouri, W. Inaoka, Y. Toida, M. Watanabe, and K. Toyoda, Zeolites
11 (1991) p. 842

60. Y. Yan, M. Tsapatsis, M.E. Davis, and G.R. Gavalas, l. Chem. Soc. Chem. Commun. (1995) p. 227.

61. J.C. Jansen and G.M. Rosmalen, J. Cryst. Growth 128 (1993) p. 1150.

62. F. Kapteijn, W.J.W. Bakker, J. van de Graaf G. Zheng, J. Poppe, and J.A. Moulijn, Catal. Today 25 (1995) p. 213.

63. M.D. Jia, K.V. Peinemann, and R.D. Behling, J. Membr. Sci. 82 (1993) p. 15.

64. E.R. Geus, M.J. Denexter, and H. van Bekkum, J. Chem. Soc.- Faraday Trans. 88 (20) (1992) p. 3101.

65. Y. Kiyozumi, F. Mizukami, K. Maeda, T. Kodzasa, M. Toba, and S. Niwa, Stud. Surf. Sci. Catal. 105 (1996) p. 2225

66. Y. Yan, M.E. Davis, and G.R. Gavalas, Ind. Eng. Chem. Res. 34 (1995) p. 1652.

67. H.H. Funke, M.G. Kovalchick, J.L. Falconer, and R.D. Noble, ibid. 35 (1996) p. 1575.

68. V. Valtchev and S. Mintova, Zeolites 15 (1995) p. 171

69. K. Kusakabe, T. Kuroda, A. Murata, and S. Morooka, Ind. Eng. Chem. Res. 36 (1997) p. 649. 70. C.N. Wu, K.J. Chao, T.G. Tsai, Y.H. Chiou, and H.C. Shih, Adv. Mnter. 8 (12)(1996) p. 1008. 71. M. Fang, H. Du, W. Xu, X. Meng, and W. Pang, Microporous Mater. 9 (1997) p. 59.

72. J. Koegler, A. Arafat, H. van Bekkum, and J.C. Jensen, Stud. Surf. Sci. Catal. 105 (1997) p. 2163.

73. S. Mintova, S. Mo, and T. Bein, Chem. Mater. in press.

74. S. Mintova, S. Mo, K. Yasuda, J. Visser, and T. Bein, "Microwave Synthesis of Zeolite Films for Sensor Applications," Proc. Int. Workshop on Zeolitic Membranes and Films, edited by S. Nakao and M. Matsukata (The Membrane Society of Japan, Gifu, Japan, June 28-30, 1998) p. 33 .

75. K.J. Chao, T.G. Tsai, and C.N. Wu, "Membranes with Aligned Molecular Sieve Crystals," ibid., p. 5-8.

76. N. Nishiyama, T. Matsufuji, K. Ueyama, and M. Matsukata, Microporous Mater. 12 (1997) p. 293.

77. N. Nishiyama, K. Ueyama, and M. Matsukata, J. Chem. Soc. Chem. Commun. (1995) p. 1967.

78. Y. Yan, M.E. Davis, and G.R. Gavalas, J. Membr. Sci. 123 (1997) p. 95

79. M. Nomura, T. Yamaguchi, and S. Nakao, Ind. Eng. Chem. Res. 36 (1997) p. 4217.

80. M.C. Lovallo and M. Tsapatsis, "Nanocrystalline Zeolites: Synthesis, Characterization, and Application with Emphasis on Zeolite L Nanoclusters," in Advanced Techmiques in Catalyst Synthesis, edited by W. Moser (Academic Press, 1996).

81. Ibid., AlChE I. 42 (1996) p. 3020.

82. W.F. Lai, H.W. Deckman, J.A. McHenry, and J.P. Verduijn, International Patent Application No. WO 96/01687 (1996).

83. M.C. Lovallo, A. Gouzinis, and M. Tsapatsis AlChE J. 44 (8) (1998) p. 1903.

84. L.C. Boudreau and M. Tsapatsis, Chem. Mater. 9 (8) (1997) p. 1705.

85. M.C. Lovallo, M. Tsapatsis, and T. Okubo, ibid. 8 (1996) p. 1579.

86. K.J. Balkus, Jr., and M.E. Gimon-Kinsel, ibid. 10 (1998) p. 464.

87. G. Xomeritakis, A. Gouzinis, S. Nair, M Tsapatsis, M. He, R. Overney, and T. Okubo, Chem. Eng. Sci. in press, 1999.

88. A. Gouzinis and M. Tsapatsis, Chem. Mater. 10 (9) (1998) p. 2497.

89. H. Suzuki, U.S. Patent No. 4,699,892 (1987). 90. H. Kita, "Pervaporation Using Zeolite Membranes," Proc. Int. Workshop on Zeolitic Membranes and Films, edited by S. Nakao and M. Matsukata (The Membrane Society of Japan, Gifu, Japan, June 28-30, 1998) p. 43.

91. K. Keizer, A.J. Burggraaf, Z.A.E.P. Vroon, and H. Verweij, J. Membr. Sci. 149 (1998) p. 159. 92. C.D. Baertsch, H.H. Funke, J.L. Falconer, and R.D. Noble, I. Phys. Chem. 100 (1996) p. 7676.

93. G. Xomeritakis and M. Tsapatsis, Chem. Mater in press.

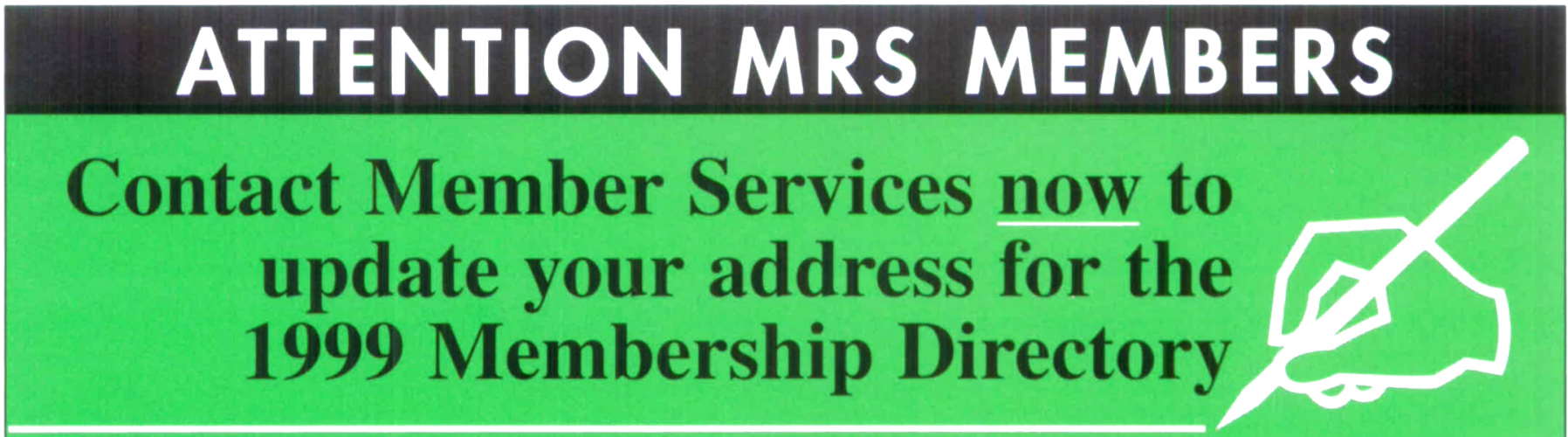

Deadine for listing updates is May 15, 1999

Tel: 724-779-3003 • Fax: 724-779-8313 •E-mail: info@mrs.org 